\title{
Мотивационная структура профессиональной деятельности медицинских работников России
}

\author{
А.Л. ТЕМНИЦКИЙ*
}

\begin{abstract}
*Александр Лазаревич Темницкий - кандидат социологических наук, доцент кафедры социологии, Московский государственный университет (институт) международных отношений МИД РФ (МГИМО); старший научный сотрудник, Институт социологии Федерального научно-исследовательского социологического центра РАН. Адрес: 119454, Москва, проспект Вернадского, д. 76. E-mail: taleksandr@list.ru
\end{abstract}

Цитирование: Темницкий А.Л. (2021) Мотивационная структура профессиональной деятельности медицинских работников России // Мир России. Т. 30. № 4. С. 30-52. DOI: $10.17323 / 1811-038 X-2021-30-4-30-52$

В статье анализируется структура мотивации медицинских работников, которая раскрывается сквозь призму мотивов-побуждений, стимулов к труду и удовлетворенности различными сторонами труда. Отдельное значение придается выявлению ее устойчивости во времени и по отношению к различнылм контрольнылм факторам: статусной, региональной, организационной, квалификационной и половозрастной принадлежности медицинских работников. В качестве информационной базы исследования использовались данные трех повторных сочиологических исследований, проведенных в трех регионах России в 2014-2018 г2. по программе фундаментальных исследований НИУ ВШЭ.

В статье отмечается, что ожидаемой самодетерминации ведущих стимулов к хорошей работе и факторов удовлетворенности трудом замечено не было. Выявленная в результате анализа структура мотивации профессиональной деятельности медицинских работников бюджетной сферы была названа консервативной. Ядро такой структуры образуют мотивы и стимуль, связываемые с внешними побудителями к хорошей работе, а не с активизацией внутренних ресурсов. Их концентрированным выражением стали требования, направленные к государству. Справедливая оплата труда и наличие хорошего современного оборудования являются ведущими в составе факторов мотивации медицинских работников к более качественному и производительному труду.

Ключевые слова: структура мотивации, определяющие мотивы, стимулы к труду, удовлетворенность трудом, факторы-мотиваторы, факторы гигиены, мотив милосердия, теория самодетерминации, медицинские работники 


\section{Проблема и методология исследования}

Реформирование российского здравоохранения, начавшееся в 2010 г., проводилось под лозунгами его дальнейшей коммерциализации, оптимизации, реструктуризации и т. д., а врачи позиционировались как специалисты, оказывающие услуги населению, которые следует привести в соответствие с европейскими стандартами оказания бесплатной медицинской помощи. Проводимые реформы спровоцировали множество ценностных конфликтов в профессиональной деятельности врачей, отмечаемых многими исследователями. В сложившейся ситуации «врач больше ответствен перед инстанциями, внешними для медицинского дела как такового (государством, страховой компанией, начальством), чем перед коллегами и тем более пациентом» [Николаев 2015, с. 623]. Выявлено, что несовершенство нормативной базы в области здравоохранения, низкое качество образования у будущих медицинских работников, расширение спектра платных медицинских услуг, незаинтересованность в излечении больного привели к тому, что социальный конфликт «врач-пациент» по масштабам распространенности в российском обществе носит общенациональный характер [Семина 2016, с. 88].

Неоднозначными по направленности и последствиям выглядят усилия по внедрению в сферу бюджетного здравоохранения условий оплаты труда по принципам эффективного контракта. Задача перехода на эффективный контракт в бюджетной сфере была сформулирована В.В. Путиным в 2012 г. как необходимость получения врачом, учителем на своей основной работе зарплаты достаточной, чтобы не искать заработков на стороне. В широком понимании эффективный контракт может рассматриваться как система мер по усилению трудовой мотивации работников к качественному и производительному труду на основном рабочем месте за счет повышения уровня и изменения условий оплаты их труда [Шиикин, Темницкий 2020, с. 179].

В настоящее время, когда подведены результаты внедрения эффективного контракта, стали очевидны упущения в управлении этим процессом [Шишкин, Teмниикий 2020]; становится заметным фундаментальное противоречие между гуманитарной компонентой в профессиональной деятельности врача и ее сведением по условиям данного контракта к сугубо денежной мотивации труда при игнорировании роли других мотивов. Следует признать, что работа медика не относится к легко просчитываемым для внедрения различных показателей по оплате. Вопрос « $<$..> что считать результатом труда, не может быть решен стандартным образом, требует учета спецификации профессиональной деятельности вплоть до уровня каждого рабочего места медицинского работника» [Стародубов, Кадыров 2013, с. 14]. К числу наиболее явных изъянов, обнаруженных по результатам анализа внедрения эффективного контракта, были отнесены непрозрачность в оплате труда, отсутствие видимой связи между размерами оплаты и результатами труда, низкая степень дифференцированности в оплате [Шиикин, Темниикий 2020, с. 199]. Но даже если допустить возможность максимально полной проработки всех параметров заработной платы медицинских работников, самые важные стороны профессии медика (милосердие и сострадание к больному, моральные принципы профессиональной деятельности) остаются вне зоны воздействия экономической политики.

Определение мотивации трудовой деятельности медицинских работников в узком смысле как «степени готовности человека проявлять и поддерживать усилия 
по достижению целей организации» [Franco et al. 2002; Чирикова (1) 2019, с. 56] многие исследователи считают удачным. Такое определение адекватно для сегодняшней ситуации мобилизационной медицины [Хуснутдинова, Хайруллина 2020], но не является полным при комплексном подходе к анализу мотивации при рассмотрении врача как человека с выбранной профессией, а не организации. Обратное определение мотивации можно дать, если исходить из соответствия трудовой деятельности не организационным, а профессиональным целям, критериям врача как представителя профессии с особыми правилами игры и высоким уровнем саморегулирования. В этом случае это определение может звучать как степень готовности проявлять и поддерживать усилия по укреплению ресурсов власти профессиональной группы, сохранению ее независимости от административного влияния, обеспечению привилегий и престижа в обществе. Первое определение соответствует представлению о враче как о государственном служащем, второе - как о свободном профессионале. Первое ближе к традициям советской медицины, второе - западной [Мансуров, Юрченко 2005]; первое отдает приоритет внешней, второе - внутренней мотивации, которая рассматривается как стремление субъекта трудовой деятельности выполнять работу ради интереса к самому процессу работы. Такая мотивация сохраняется даже в отсутствие внешних наград и при применении наказаний; внешняя мотивация как побуждение к деятельности, не связанное с содержанием самой деятельности, ассоциируется, как правило, со стимулированием.

Актуальной является модель согласования внутренней и внешней мотивации при сохранении ведущей роли первой. Отражением такого видения можно считать теорию самодетерминации, авторы которой установили, что денежные стимулы могут вытеснять внутреннюю мотивацию [Deci, Ryan 1985, p. 48]. В основе теории самодетерминации лежит удовлетворение базовых психологических потребностей в автономии, компетентности и взаимосвязи с другими людьми [Ryan, Deci 2017], реализация которых контролируется общепринятыми нормами, правилами, профессиональными кодексами или факторами внешней мотивации [Осин, Иванова, Гордеева 2013]. Следует учитывать, что авторы теории самодетерминации не сводят внешнюю мотивацию только к экстернальной и контролируемой регуляции (деятельности ради получения внешних наград и избегания негативных санкций). Помимо указанной, они выделяют еще три ее вида, слабо либо вовсе не контролируемой извне. Деятельность, побуждаемая внутренними наградами и наказаниями, такими как переживание гордости, чувство вины или условная самооценка, была названа интроецированной регуляцией. Деятельность, осуществляемая субъектом ради достижения целей, которые выбраны им осознанно и субъективно, как, например, карьерный рост, получила название идентифицированной регуляции. Деятельность, переживаемая как часть собственной идентичности, как, например, призвание, названа интегрированной регуляцией [Ryan, Deci 2000, p. 72].

В этой связи самодетерминация может пониматься как способность и готовность работника к преобразованию внешних стимулов, целей и ценностей в процесс удовлетворения базовых профессиональных потребностей. Так, о процессе самодетерминации ведущих стимулов к работе можно было бы говорить, если бы, например, справедливость в оплате труда как главный стимул положительно коррелировала с самостоятельностью в решении профессиональных задач.

Безусловно, профессиональная деятельность медицинских работников, которую мы изначально рассматриваем как полимотивированную [Шишкин, Темниикий, 
Чирикова 2013, с. 35], не исчерпывается удовлетворением трех указанных базовых потребностей. В социологических исследованиях важно выделять те мотивы, которые исходят из социальных потребностей и являются актуальными в настоящее время, а не обращены к выявлению идеальных представлений либо являются базовыми на психологическом уровне. Это объясняется, прежде всего, преобладающим влиянием для медицинских работников сегодняшнего дня, статуса профессии в обществе, состояния сферы здравоохранения, медицинской организации, возможностей улучшения своего положения не в отдаленной перспективе, а в ближайшее время.

Структура мотивации, под которой будем понимать распределение мотивов и стимулов в иерархии их важности по оценкам работников, изучается на основе множества теорий и методик, каждая из которых имеет свои собственные достоинства и недостатки. Обобщение теоретической и эмпирической литературы, имеющей отношение к мотивации врачей, показывает, что (1) степень мотивации определяется многочисленными факторами; (2) прямое объективное измерение мотивации как психологического состояния затруднено; (3) полезные косвенные (опосредованные) показатели мотивации могут быть уточнены и измерены по субъективным оценкам с помощью опросов; (4) относительная значимость факторов мотивации различается в зависимости от служебного статуса и профиля деятельности врача, его пола, возраста, этапа карьеры и поколения [Dolea, Adams 2005].

Исходя из этого, наш подход к выявлению структуры мотивации медицинских работников состоит из выделения трех компонентов, раскрывающих ее внутренние, внешние и оценочные стороны, использования косвенных показателей мотивации, получаемых по субъективным оценкам с помощью опросов, учета всех возможных объективных детерминант мотивации. Такой комплексный анализ позволит получить ответы на весьма сложные по содержанию и их последующей интерпретации вопросы: что побуждает к работе, что может улучшить отношение к ней и что вызывает удовлетворенность в повседневной профессиональной деятельности медицинских работников современной России.

Цель исследования состоит в выявлении структуры мотивации труда медицинских работников, ее ядра и периферии, определении ее устойчивости во времени и по отношению к различным контрольным срезам: статусной, региональной, организационной квалификационной и половозрастной принадлежности.

Основной методической задачей является обоснование набора индикаторов для измерения мотивации профессиональной деятельности медицинских работников. Важнейшая исследовательская задача связана с проверкой гипотезы о сохранении в ядре мотивации медицинских работников признаков внутренних мотивов, прежде всего профессионального интереса, его автономии по отношению к внешним факторам (денежным стимулам), а также о сохранении и ценности для медицинских работников милосердия к больному как морально-нравственной основы их профессиональной деятельности.

\section{Методика исследования}

Выявление мотивов-побуждений к труду основывалось на предварительном выделении актуальных для медицинских работников социальных потребностей 
с опорой на теорию иерархии потребностей А. Маслоу [Маслоу 2016], их соотнесения с приоритетными ценностными ориентациями, характерными для медицинских работников (таблица 1). При этом мы не придерживаемся подхода А. Маслоу о последовательности в реализации указанных потребностей. Так, потребность в милосердии с ориентацией на сострадание и помощь больному оценивается нами как потенциально согласуемая со всеми выделенными социальными потребностями, но максимально воплощаемая на уровне самореализации. Проверить данную гипотезу можно по результатам корреляционного анализа.

\section{Таблица 1. Взаимосвязь социальных потребностей с ценностными ориентациями и отдельными мотивами}

\begin{tabular}{|c|c|c|}
\hline $\begin{array}{l}\text { Социальные } \\
\text { потребности }\end{array}$ & Ценностные ориентации & Мотивы \\
\hline $\begin{array}{l}\text { Экзистенционально- } \\
\text { сохранительные }\end{array}$ & $\begin{array}{l}\text { Ориентация на сохранение занятости; } \\
\text { обеспечение материального благопо- } \\
\text { лучия семьи }\end{array}$ & $\begin{array}{l}\text { Гарантированная занятость; } \\
\text { возможность заработать } \\
\text { деньги на жизнь }\end{array}$ \\
\hline Социальные связи & $\begin{array}{l}\text { Ориентация на ближний круг сетевого } \\
\text { взаимодействия, на наращивание } \\
\text { и укрепление социальных сетей } \\
\text { ближнего круга отношений с друзьями, } \\
\text { знакомыми, коллегами, устойчивыми } \\
\text { группами пациентов }\end{array}$ & $\begin{array}{l}\text { Возможность при необходимости } \\
\text { помочь близким, друзьям, } \\
\text { себе в сохранении здоровья; } \\
\text { возможность завоевать } \\
\text { уважение коллег; } \\
\text { уважение, поддержка семьи и близких } \\
\text { друзей; } \\
\text { расширение возможностей } \\
\text { общения с другими людьми }\end{array}$ \\
\hline $\begin{array}{l}\text { Прагматико- } \\
\text { утилитарные }\end{array}$ & $\begin{array}{l}\text { Ориентация на себя, свои честолюби- } \\
\text { вые интересы }\end{array}$ & $\begin{array}{l}\text { Возможность сделать карьеру; } \\
\text { профессиональный рост }\end{array}$ \\
\hline $\begin{array}{l}\text { Самореализация } \\
\text { и милосердие }\end{array}$ & $\begin{array}{l}\text { Ориентация на профессиональные } \\
\text { ценности, связанные прежде всего } \\
\text { с фигурой больного, состраданием к нему }\end{array}$ & $\begin{array}{l}\text { Профессиональный интерес, } \\
\text { сострадание и помощь больному }\end{array}$ \\
\hline
\end{tabular}

Предложение медицинским работникам посредством анкетного вопроса «какие мотивы труда, на Ваш взгляд, сегодня являются определяющими для работников системы здравоохранения?» дать свои оценки реально действующим побудителям к труду рассматривается нами как надежный инструмент косвенного, экспертного по характеру измерения реальной ситуации в мотивации к труду. Для ответа предлагался список из одиннадцати подсказок (предлагалось выбрать не более трех), а также возможность самостоятельно сформулировать свой ответ ${ }^{1}$.

В выделении стимулов к труду как факторов внешней мотивации преследовалась идея об их разделении на две группы: (1) средства получения равных для всех условий улучшения профессиональной деятельности (справедливая оплата труда, обеспечение современным оборудованием, предоставление социальных льгот, забота о сотрудниках и похвала со стороны руководства, публичное при-

1 Список конкретных мотивов составлялся с учетом исследований, проведенных А.Е. Чириковой с использованием качественных методов, согласовывался в процессе совместного обсуждения с С.В. Шишкиным. 
знание заслуг); (2) средства для активизации внутренних ресурсов (возможности зарабатывать столько, сколько можешь; получение дополнительного заработка; расширение самостоятельности в решении профессиональных задач; создание возможностей для профессионального роста, повышения квалификации; легализация неформальных платежей). Такое построение стимулов было ориентировано на выбор оптимальных стратегий управления при внедрении эффективного контракта: намечаемое повышение оплаты труда должно быть ориентировано на рост индивидуальной результативности, увязку оплаты с результирующими показателями или обеспечение соответствия денежного вознаграждения реальному уровню квалификации, компетенций. Кроме этого, выделялись негативные стимулы (реальная угроза потери рабочего места, взыскательная переаттестация), а также универсальный для всех категорий медицинских работников стимул - повышение ответственности перед пациентами и их родственниками при выполнении работы ${ }^{2}$.

\section{Таблица 2. Выделение факторов гигиены (Г) и мотиваторов (М) в формулировках вопроса $^{3}$}

\begin{tabular}{|c|c|}
\hline Что Вам нравится в Вашей работе? & Что Вам не нравится в Вашей работе? \\
\hline 1. Г. Работа без больших напряжений и стрессов & $\begin{array}{l}\text { 1. Г. Работа требует большого напряжения, часто } \\
\text { сопровождается стрессами }\end{array}$ \\
\hline $\begin{array}{l}\text { 2. М. Работа способствует личностной } \\
\text { самореализации }\end{array}$ & 2. М. Однообразная работа \\
\hline 3. Г. Близость работы к месту жительства & $\begin{array}{l}\text { 3. Г. На дорогу к работе приходится затрачивать } \\
\text { много времени }\end{array}$ \\
\hline $\begin{array}{l}\text { 4. М. Работа позволяет использовать имеющиеся } \\
\text { знания, умения и опыт }\end{array}$ & $\begin{array}{l}\text { 4. М. Работа требует постоянного повышения } \\
\text { квалификации }\end{array}$ \\
\hline 5. Г. Работа с людьми, которые нравятся & $\begin{array}{l}\text { 5. Г. Коллеги думают только о себе, надеяться } \\
\text { на их советы и помощь в работе не приходится }\end{array}$ \\
\hline $\begin{array}{l}\text { 6. М. Работа дает хорошие шансы для продвижения } \\
\text { по службе }\end{array}$ & $\begin{array}{l}\text { 6. М. Для того, чтобы продвинуться по службе, } \\
\text { надо много и долго работать }\end{array}$ \\
\hline $\begin{array}{l}\text { 7. Г. Хорошие отношения с непосредственным } \\
\text { руководством }\end{array}$ & $\begin{array}{l}\text { 7. Г. Невнимательное отношение руководства } \\
\text { к проблемам в труде и личной жизни подчиненных }\end{array}$ \\
\hline 8. М. Сложная, трудная, но интересная работа & $\begin{array}{l}\text { 8. М. Работа заставляет думать и действовать } \\
\text { самостоятельно }\end{array}$ \\
\hline 9. Г. Стабильный заработок & $\begin{array}{l}\text { 9. Г. Чтобы получить достойную зарплату, } \\
\text { надо много и упорно трудиться }\end{array}$ \\
\hline $\begin{array}{l}\text { 10. М. Признание и одобрение хорошо выполненной } \\
\text { работы }\end{array}$ & $\begin{array}{l}\text { 10. М. Высокая степень ответственности } \\
\text { за результаты выполненной работы }\end{array}$ \\
\hline 11. Г. Гибкое рабочее время и гибкий темп работы & $\begin{array}{l}\text { 11. Г. Жесткий график работы, нет возможности } \\
\text { отвлечься на дела, напрямую не связанные с работой }\end{array}$ \\
\hline 12. М. Работа требует твор & $\begin{array}{l}\text { 12. М. Работа заставляет развивать свои способности, } \\
\text { требует большого умственного напряжения }\end{array}$ \\
\hline
\end{tabular}

2 Для выявления стимулов к труду использовался вопрос с множественным выбором (не более 5) вариантов ответа из 14 подсказок: «Как Вы считаете, что могло бы более действенно стимулировать работников системы здравоохранения к лучшей работе?»

3 Методика выявления факторов удовлетворенности/неудовлетворенности использовалась только в исследовании 2018 г. 
Выявление факторов удовлетворенности и неудовлетворенности работой проводилось с использованием теории Ф. Херцберга. Уточним, что, согласно двухфакторной теории мотивации труда Ф. Херцберга, факторы гигиены - это те, которые сами по себе не вызывают удовлетворенность, но при их ухудшении порождают неудовлетворенность работой (отношения с коллегами, начальством, вознаграждение, условия труда, стабильность занятости). Напротив, факторы-мотиваторы - это те, которые непосредственно вызывают удовлетворенность работой, высокий уровень мотивации (самостоятельность, ответственность, личностная самореализация) [Хериберг, Моснер, Блох Снидерман 2007]. С учетом методики Ф. Херцберга были разработаны два закрытых, зеркальных по отношению друг к другу вопроса, в которых выделялись индикаторы факторов гигиены и мотиваторов (таблица 2).

\section{Описание выборки}

В качестве информационной базы исследования использовались данные трех повторных социологических исследований, проведенных в трех регионах России в 2014-2018 гг. по программе фундаментальных исследований НИУ ВШЭ 4 . Выборка опрашиваемых лиц охватывает все основные категории медицинских работников и наиболее распространенные типы учреждений здравоохранения. Респондентами выступали главные врачи, врачи, средний медицинский персонал (СМП) и младший медицинский персонал (ММП) в центральных районных больницах, городских больницах и поликлиниках, областных больницах, станциях скорой помощи. Полевой этап исследований был выполнен в 2014 г. Центром Юрия Левады, в 2016 и 2018 гг. - компанией «S-медиа». Для анализа использовались данные по трем регионам: Москвы, Вологодской и Воронежской областей. Отбор регионов осуществлялся с учетом показателей номинальной начисленной заработной платы работников организаций, а также врачей и других медицинских работников, имеющих высшее образование. Самое высокое положение здесь занимает Москва, среднее - Вологодская область, более низкое - Воронежская область [Регионы России 2019, с. 200, 206]. Каждый регион представлен примерно равной численностью респондентов. Распределение выборки внутри каждого региона по типам медицинских учреждений осуществлялось пропорционально заданной численности респондентов, занятых в соответствующих типах учреждений (таблица 3). Полученные данные не претендуют на точность количественных оценок применительно ко всей сфере бюджетного здравоохранения. Валидность и надежность результатов аналитики обеспечивают использование данных трех повторных социологических исследований, проведенных в одних и тех же регионах по единой методике и инструментарию. Опрос был проведен методом формализованного интервью по месту работы респондентов.

\footnotetext{
4 Все исследования проводились под руководством профессора В.С. Шишкина. Автор статьи принимал участие в разработке инструментария и анализе данных проведенных исследований.
} 
Таблица 3. Распределение должностных категорий медицинских работников по годам опроса, \%

\begin{tabular}{|l|c|c|c|}
\hline Доляннстные категории & $\mathbf{2 0 1 4}$ & $\mathbf{2 0 1 6}$ & $\mathbf{2 0 1 8}$ \\
\hline Главные врачи & 3 & 4 & 3 \\
\hline Врачи & 54 & 55 & 54 \\
\hline Средний медицинский персонал (СМП) & 31 & 29 & 30 \\
\hline Младший медицинский персонал (ММП) & 12 & 12 & 13 \\
\hline Всего & 100 & 100 & 100 \\
\hline Количество респондентов & $\mathbf{1 3 2 6}$ & $\mathbf{1 3 8 1}$ & $\mathbf{2 0 3 1}$ \\
\hline
\end{tabular}

Тройку наиболее значимых мотивов к труду образуют профессионализм (профессиональный интерес к работе), милосердие (сострадание и помощь больному) и деньги (возможность их заработать в данных сложившихся условиях). Выбор трех указанных мотивов был всегда характерен примерно для половины респондентов. Все остальные мотивы существенно уступают первым трем, и эти различия являются устойчивыми по отношению ко всем годам опроса. Однако нельзя не заметить, что по сравнению с 2014 г. роль мотива сострадания к больному снизилась. Определенные коррективы в распределение трех определяющих мотивов вносит региональный фактор: медицинские работники Москвы отдают предпочтение деньгам по сравнению с мотивом сострадания к больному (48 и 39\% соответственно), примерно такие же различия характерны и для медиков Вологодской области (48 и $37 \%$ соответственно), и только у представителей менее благополучного региона (Воронежская область) деньги уступают мотиву сострадания (38 и 43\% соответственно); эти различия стали заметными лишь по данным 2018 г.

\section{Структура определяющих мотивов}

Выявление иерархии мотивов трудовой деятельности, ее устойчивости проводилось по отношению к годам опросов и применительно к различным категориям медицинских работников. Рассмотрим в динамике выявленную иерархию значимости определяющих мотивов труда (таблица 4).

В еще большей мере на распределение трех ведущих мотивов влияет должностной статус. Мотив профессионального интереса не играет существенной роли для ММП (23\%) и явно преобладает по оценкам главных врачей $(87 \%$, по данным 2018 г.). Напротив, мотив сострадания и помощи больному во все годы исследований в наименьшей степени поддерживался главными врачами $(30 \%)$ и не имел существенных различий у других должностных категорий. Пониженная роль мотивов профессионального интереса и сострадания к больному характерна для медицинских работников станций скорой помощи по сравнению со всеми остальными типами медицинских учреждений, тогда как важность мотива денег 
остается примерно одинаковой для всех типов учреждений. Неоднозначное влияние оказывают половозрастные особенности медиков: у мужчин по всем годам опроса существенно большее значение имеют профессиональный интерес и деньги, и меньшее - сострадание к больному. Роль профессионального интереса с возрастом снижается, а значение денежного вознаграждения возрастает, тогда как значение мотива сострадания не различается. Не оказывает существенного влияния на распределение значений трех указанных мотивов уровень профессиональной квалификации медиков. В целом, несмотря на выявленные различия, мотивы профессионального интереса, сострадания больному и денег являются определяющими для всех категорий медицинских работников, за исключением представителей станций скорой помощи и ММП, у которых третье место занимает мотив гарантированной занятости. Он стоит на четвертой позиции в структуре мотивов труда медиков и связан с возросшим страхом потерять работу в результате известных мероприятий по оптимизации сферы здравоохранения, а также внедрения эффективного контракта [Темницкий 2018].

Таблица 4. Иерархия мотивов, определяющих работу медицинских работников в динамике 2014-2018 гг., \%*

\begin{tabular}{|l|c|c|c|}
\hline Определяющие мотивы & $\mathbf{2 0 1 4}$ & $\mathbf{2 0 1 6}$ & $\mathbf{2 0 1 8}$ \\
\hline Профессиональный интерес & 62 & 61 & 61 \\
\hline Сострадание и помощь больному & 52 & 43 & 44 \\
\hline Возможность заработать деньги на жизнь & 49 & 49 & 46 \\
\hline Гарантия занятости & 32 & 32 & 34 \\
\hline $\begin{array}{l}\text { Возможность при необходимости помочь близким, друзьям, } \\
\text { себе в сохранении здоровья }\end{array}$ & 29 & 32 & 28 \\
\hline Профессиональный рост & 19 & 18 & 21 \\
\hline $\begin{array}{l}\text { Невозможность устроиться в регионе на другую оплачивае- } \\
\text { мую работу по медицинской специальности }\end{array}$ & 9 & 9 & 6 \\
\hline Уважение, поддержка семьи и близких друзей & 9 & 5 & 6 \\
\hline Возможность сделать карьеру & 5 & 5 & 6 \\
\hline Расширение возможностей для общения с людьми & 4 & 3 & 5 \\
\hline Возможность завоевать уважение коллег & 3 & 2 & 3 \\
\hline Количество ответивших & $\mathbf{1 3 1 3}$ & $\mathbf{1 3 5 0}$ & $\mathbf{1 9 9 8}$ \\
\hline
\end{tabular}

*Суммы по столбцам превышают 100\%, т. к. можно было выбрать до 3 вариантов ответа.

Мотив «возможность при необходимости помочь близким, друзьям, себе в сохранении здоровья» связывается нами с потребностью во взаимосвязи с другими людьми. Однако обнаружить его значимую корреляцию с другими мотивами, выступающими проводниками в реализации этой базовой согласно теории само- 
детерминации потребности (завоевать уважение коллег, поддержку семьи, общение с людьми), не удалось. В наибольшей мере мотив помощи близким, друзьям в сохранении здоровья характерен для СМП, медиков, работающих в районных и областных больницах, представителей женского пола. Данный мотив образует отдельный кластер и имеет выраженный инструментальный характер, что проявляется в более толерантном по сравнению с другими мотивами отношении к получению дополнительного вознаграждения от пациентов и родственников, большей включенности в дополнительную работу как в своем учреждении, так и вне сферы здравоохранения. По содержанию он может быть назван кластером «социальных капиталистов» и в целом отражает, на наш взгляд, мотивационную ситуацию трудовой деятельности непривилегированной части СМП и врачей, которые либо еще не добились достойного для нормальной жизни материального уровня и статусного положения в организации, либо, будучи неудовлетворенными сложившимся положением, занимаются поиском дополнительных возможностей для решения своих прагматических интересов.

Остальные мотивы ни по одному из годов опроса и учитываемым категориям медицинских работников не набрали более $20 \%$ и могут рассматриваться как периферийные.

Отдельного рассмотрения требуют первые три наиболее значимых мотива. При проведении кластерного анализа они, как правило, образуют единый, самый большой по численности кластер (не менее 65\%, в 2018 г. - 69\%), который характеризуется сочетанием трех дополняющих друг друга определяющих мотивов трудовой деятельности: профессионального интереса, сострадания и помощи больным, получение финансового вознаграждения. Его можно назвать кластером «разносторонних»- в смысле сильной выраженности одновременно профессиональных, духовных и материальных мотивов. Однако в аналитическом плане важно изучить отдельно каждый из трех мотивов в данном кластере, поскольку их математическое единение по модулю расходится с содержательным пониманием и результатами корреляционного анализа (между мотивами профессионального интереса и состраданием к больному всегда выявляется значимая положительная, а по отношению к возможности заработать деньги - отрицательная связь). Наличие отрицательной корреляции между мотивами профессионального интереса и возможности заработка может рассматриваться как одно из свидетельств сохранения относительной автономии первого.

\section{Мотив сострадания больному в противовес денежном интересу}

Милосердие как деятельное сострадание и желание помочь больному являлось нормой жизни для медицинских работников дореволюционной России, но перестало быть ею при советской власти, когда в 1920-е гг. были ликвидированы все общества милосердия, а культура медицинского ухода трансформировалась в худшую сторону, и профессия медсестры превратилась в заурядное ремесленничество [Лопатина 2009]. Сегодня милосердное отношение к пациентам является явно дефицитным, и его роль явно занижена как при профессиональной подготовке будущих медиков [Поскотина 2009], так и при внедрении таких организационных 
инноваций, как эффективный контракт, оптимизация сферы здравоохранения в целом. В современном лексиконе чаще используется термин «альтруизм», чем милосердие. Хотя эти понятия и являются тождественными, мы будем придерживаться термина «милосердие», поскольку в нем подчеркивается важность нравственной компоненты, тогда как альтруизм профессионалов-врачей стал восприниматься как составная часть идеологии для формирования благоприятного публичного образа профессии [Мансуров, Юрченко 2010, с. 404].

Обладают ли движущей силой указания на определяющую роль мотива милосердия в ответах медицинских работников? Для ответа на этот вопрос были созданы две противоположные типологические категории медиков с наличием и отсутствием мотива сострадания и помощи больному в соотношении с мотивом заработать деньги. В качестве отдельной рассматривалась категория, в которой имели место оба мотива (таблицуа 5).

Таблица 5. Типологические категории медицинских работников по соотношению мотивов сострадания больному и возможности заработать деньги ${ }^{5} \%$

\begin{tabular}{|l|c|c|c|}
\hline Категории & $\mathbf{2 0 1 4}$ & $\mathbf{2 0 1 6}$ & $\mathbf{2 0 1 8}$ \\
\hline $\begin{array}{l}\text { Наличие мотива сострадания больному и отсутствие мотива } \\
\text { заработать деньги }\end{array}$ & 40 & 33 & 37 \\
\hline $\begin{array}{l}\text { Наличие мотива заработать деньги и отсутствие мотива } \\
\text { сострадания больному }\end{array}$ & 36 & 47 & 44 \\
\hline $\begin{array}{l}\text { Наличие мотивов сострадания больному и возможности } \\
\text { заработать деньги }\end{array}$ & 24 & 20 & 19 \\
\hline Количество ответивших & $\mathbf{1 0 6 7}$ & $\mathbf{1 1 4 6}$ & $\mathbf{1 6 8 8}$ \\
\hline
\end{tabular}

По сравнению с 2014 г. произошло снижение как мотива с «чистым» состраданием больному, так и его соединения с мотивом заработка и возросла доля тех, кто указывал на роль денег и отрицал при этом сострадание больному. Предполагалось, что по мере внедрения эффективного контракта еще больше будет снижаться роль мотива сострадания и расти роль денежного интереса, однако вне зависимости от того, заключался ли с медицинскими работниками эффективный контракт или нет, а также с учетом контрольных факторов (региона, должностного статуса, типа медицинского учреждения) различий в принадлежности к построенным типологическим категориям не выявлено, нет и существенных различий в размерах получаемого заработка. Некоторые устойчивые различия наблюдаются лишь по половозрастным характеристикам: для медицинских работников мужского пола во все годы опроса было свойственно преуменьшать роль мотива сострадания больному. Также притупление мотива сострадания происходит с возрастом: наименьшее выражение он получает после 50 лет, одновременно растет значение денежного интереса.

\footnotetext{
5 Из анализа исключена типологическая категория респондентов, указавших на любые другие мотивы, кроме сострадания и денег.
} 
Незначительное влияние объективных характеристик на выраженность мотива сострадания больному позволяет предположить, что его наличие в структуре определяющих мотивов медицинских работников обусловлено их моральными качествами, а также практиками построения отношений с пациентами. Наиболее явно это проявляется в оценках практик неформальных платежей. Так, медицинские работники с явно выраженной мотивацией сострадания и помощи больному в отличие от тех, кто возвеличивает роль денег и исключает роль сострадания, в 2 раза реже полностью соглашаются с тем, что материально обеспеченные пациенты должны оплачивать медицинские услуги врачей (6 и 13\% соответственно), а большинство из них (60\%) совершенно не согласны с такой практикой (в противоположной группе таких $47 \%)^{6}$. Ориентация на сострадание и помощь больному чаще сопровождается поисками адекватного понимания пациента, большего интереса к тем пациентам, которые задают вопросы, высказывают свое мнение о болезни (70 и 54\% в противоположной группе). В отношениях с пациентами их больше беспокоит безответственное отношение к своему здоровью (63 и 48\% соответственно), неготовность к совместным усилиям по выработке согласованных решений по лечению (30 и $23 \%$ соответственно). Они чаще сетуют на то, что им мешает лучше работать произошедшее снижение уважения к работе врача в обществе (61 и $57 \%$ соответственно), при этом они в 2 раза чаще считают престижной свою профессию (определенно да -20 и $10 \%$ соответственно).

По всем годам исследования у медиков с выраженным мотивом сострадания больному по сравнению с теми, кто не считает данный мотив определяющим в работе, замечены более высокие показатели удовлетворенности существующими правилами вознаграждения за высокие результаты работы, уровнем защиты в случае возникновения конфликта с пациентами. По данным исследования в 2018 г., они чаще считают, что требовательность пациентов к качеству лечения возросла, т. к. люди стали больше дорожить своим здоровьем (27 и $18 \%$ соответственно), и реже - что это происходит под влиянием возросшей критики и нападок на медиков в СМИ (58 и $70 \%$ соответственно).

Таким образом, включенность в структуру мотивации профессиональной деятельности мотива сострадания и помощи больному способствует построению конструктивных отношений с пациентами, которые перестают быть зоной напряженности и конфликтов, не выступают, как отмечается исследователями, весомым демотивирующим фактором в работе [Чирикова (2) 2019, с. 22].

\section{Иерархия стимулов к труду}

Контролируемые в исследованиях стимулы труда медицинских работников обладают высокой степенью устойчивости, их структура не претерпела существенных изменений за все годы наблюдений (таблища б).

6 Здесь и далее приводятся данные за 2016 г., когда задавались подобные вопросы. Указанные различия значимы на уровне $\mathrm{p} \leq 0,01$. Существенных различий в типологической категории, совмещающих мотивы сострадания и заработка, не выявлено. 


\section{Таблица 6. Иерархия стимулов к лучшей работе медицинских работников в зависимо- сти от года опроса, \%*}

\begin{tabular}{|c|c|c|c|}
\hline Стимулы & 2014 & 2016 & 2018 \\
\hline Справедливая оплата труда & 93 & 89 & 84 \\
\hline Наличие хорошего современного оборудования & 49 & 50 & 50 \\
\hline $\begin{array}{l}\text { Создание возможностей для профессионального роста, } \\
\text { повышения квалификации }\end{array}$ & 30 & 35 & 34 \\
\hline $\begin{array}{l}\text { Предоставление врачам социальных льгот } \\
\text { (социального пакета) }\end{array}$ & 28 & 32 & 32 \\
\hline Забота о сотрудниках и похвала со стороны руководства & 26 & 26 & 25 \\
\hline $\begin{array}{l}\text { Предоставление возможности зарабатывать столько, } \\
\text { сколько сможешь }\end{array}$ & 24 & 25 & 19 \\
\hline $\begin{array}{l}\text { Улучшение возможности для получения дополнительного } \\
\text { заработка }\end{array}$ & 17 & 17 & 16 \\
\hline $\begin{array}{l}\text { Признание со стороны коллег, профессионального } \\
\text { сообщества }\end{array}$ & 17 & 16 & 15 \\
\hline $\begin{array}{l}\text { Повышение ответственности перед пациентами } \\
\text { и их родственниками при выполнении работы }\end{array}$ & 19 & 13 & 11 \\
\hline $\begin{array}{l}\text { Публичное признание заслуг } \\
\text { (звания, награды, освещение в СМИ) }\end{array}$ & 12 & 14 & 15 \\
\hline Реальная угроза потери рабочего места & 10 & 9 & 11 \\
\hline $\begin{array}{l}\text { Расширение самостоятельности в решении } \\
\text { профессиональных задач }\end{array}$ & 9 & 9 & 9 \\
\hline Взыскательная переаттестация & 4 & 3 & 5 \\
\hline $\begin{array}{l}\text { Легализация неформальных платежей } \\
\text { (оплата услуг в «конвертах») }\end{array}$ & 4 & 2 & 3 \\
\hline Количество ответивших & 1100 & 1181 & 1719 \\
\hline
\end{tabular}

*Суммы по столбцам превышают 100\%, т. к. можно было выбрать до 5 вариантов ответа.

Справедливая оплата труда является главным стимулом для всех категорий медицинских работников, все остальные ему существенно уступают. Еще примерно для половины медиков определяющим фактором лучшей работы является «наличие хорошего современного оборудования». В целом два первых наиболее значимых стимула отражают требования, направленные к государству, а третий (создание возможностей для профессионального роста, повышения квалификации), характерный примерно для одной трети медиков, - к менеджменту организаций. Эти стимулы по своей значимости не имеют существенных различий у представителей различных должностных категорий, типов медицинских учреждений, регионов, а также половозрастных характеристик. Еще два стимула, вошедших 
в пятерку наиболее значимых (предоставление социальных льгот и забота о сотрудниках), также имеют содержание, не связываемое с активизацией внутренних ресурсов. Не оказывают влияния на изменение позиций в пятерке ведущих стимулов к труду факт заключения эффективного контракта и получение стимулирующих надбавок, а также размеры получаемой зарплаты. Исключением являются высокооплачиваемые медицинские работники Москвы с зарплатой свыше 60 тыс. руб. в месяц (при средней по выборке - 46 тыс. руб., по данным 2018 г.). У них заметно снижается роль стимулов справедливой оплаты труда (до 74\%), наличия современного оборудования (41\%), растет роль угрозы потерять рабочее место (17\%). Содержание пяти ведущих стимулов к труду показывает, что повышение заработной платы в соответствии с национальным проектом 2012 г. рассматривается преимущественно не как стимул для активизации внутренних ресурсов к лучшей работе, а как возвращение долгов по оплате труда и внимания к труду медиков со стороны государства.

Стимулы, предполагающие предоставление больших возможностей для активизации внутренних ресурсов (возможности зарабатывать столько, сколько можешь, получения дополнительного заработка), ранее затрагивали примерно четверть опрошенных, но к 2018 г. их вес не составил и пятой части. Можно предположить, что уменьшение их роли связывается с возросшими объемами работы, ее перегруженностью, на которые чаще всего ссылаются медицинские работники при раскрытии факторов неудовлетворенности в организации труда. Улучшение возможности для дополнительного заработка больше всего может стимулировать молодых медицинских работников (18-35 лет). Из всего набора контролируемых в исследовании нематериальных стимулов для активизации внутренних ресурсов последнее место занимает расширение самостоятельности в решении профессиональных задач: ее крайне низкое значение можно объяснить отсутствием запроса на самостоятельность. Ранее было показано, что российские работники являются аутсайдерами по ценности самостоятельности в работе в сравнении с другими странами [Темницкий 2019]. В результате анализа выяснилось, что чаще других на значимость самостоятельности в работе в качестве стимула указывают медики с зарплатой свыше 60 тыс. руб., работающие в Москве, занятые на станциях скорой помощи (по данным 2018 г.). Здесь следует уточнить, что у медицинских работников Москвы замечена положительная связь стимула самостоятельности в работе с получением неформальных платежей, возможностями для дополнительной работы, а также повышением ответственности перед родственниками.

Не в почете среди возможных стимулов факторы ближайшей и внешней среды окружения (признание коллег, ответственность перед пациентами, признание в обществе, СМИ). Не стало заметным стимулом к работе и повышение ответственности перед пациентами и их родственниками при выполнении работы, более того, его роль последовательно снижалась (с 19\% в 2014 г. до 11\% в 2018 г.). Указания на определяющую роль мотива сострадания к больному при исключении мотива денег повышают значение ответственности перед пациентами, но незначительно (до 14\%, по данным 2018 г.).

На периферии возможных стимулирующих факторов к лучшему труду оказались негативные для личности медицинского работника стимулы (угроза потери рабочего места, взыскательная переаттестация). На последнем месте у всех выделяемых групп находится стимул легализации неформальных платежей, возможно, 
из-за нереальности их официального признания. Обнаруженные позиции периферийных стимулов имеют равное отношение ко всем должностным категориям медиков.

О процессе самодетерминации ведущих стимулов к работе можно было бы говорить, если бы, например, справедливость в оплате труда положительно коррелировала с факторами внутренних резервов в активизации профессиональной деятельности (предоставлением возможности зарабатывать столько, сколько сможешь, возможностями для дополнительного заработка и расширения самостоятельности в решении профессиональных задач). Однако если, по данным предыдущих исследований, такая связь устанавливалась, образовывала единый фактор и была характерна примерно для пятой части врачей [Темниикий 2017, с. 73], то в исследованиях 2014-2018 гг. связей подобного рода не обнаруживалось. Зато устойчиво воспроизводился фактор, образуемый на основе корреляций справедливости в оплате труда со всеми остальными переменными, образующими пятерку указанных выше стимулов. Такой фактор можно условно назвать фактором патерналистской справедливости. Дополнительным подтверждением является установленная связь между указаниями на важность стимула справедливой оплаты и неготовностью работать гораздо лучше у $70 \%$ врачей против $60 \%$ среди тех, для кого стимул справедливости в оплате труда не важен.

Следовательно, ожидаемой самодетерминации ведущих стимулов к труду не происходит, вектор их направленности обращен к созданию внешних, равных для всех условий улучшения профессиональной деятельности, а не к изысканию внутренних резервов.

\section{Факторы гигиены и факторы-мотиваторы в структуре мотивации}

Сначала рассмотрим выявленную иерархию факторов удовлетворенности и неудовлетворенности работой (рисунок 1). Первые два места, характерные для выбора большей части медицинских работников вне зависимости от занимаемых служебных позиций, типа лечебного учреждения, уровня квалификации и стажа работы, заняли два фактора: один - из блока «мотиваторов» - возможность благодаря работе использовать имеющиеся компетенции; другой - из блока «гигиены»стабильный заработок. Между ними нет корреляции, что позволяет предположить возможность образования на их основе самостоятельных кластеров.

В целом по обнаруженной иерархии нельзя утверждать о явном преобладании одной группы факторов над другой, поскольку они последовательно чередуют друг друга, и на этом основании можно было бы сделать вывод об их взаимодополняемости. Однако наша задача состоит в выявлении мотивационного эффекта этих групп факторов, и для этого рассмотрим иерархию факторов неудовлетворенности работой (рисунок 2).

Лидером в формировании состояния неудовлетворенности работой является высокий уровень напряжения и стрессов на работе. Эта проблема является актуальной для двух третей медицинских работников и в равной мере для всех типов медицинских учреждений; чаще всего на нее указывают главврачи, врачи и СМП, реже - представители ММП; все остальные факторы неудовлетворенности 


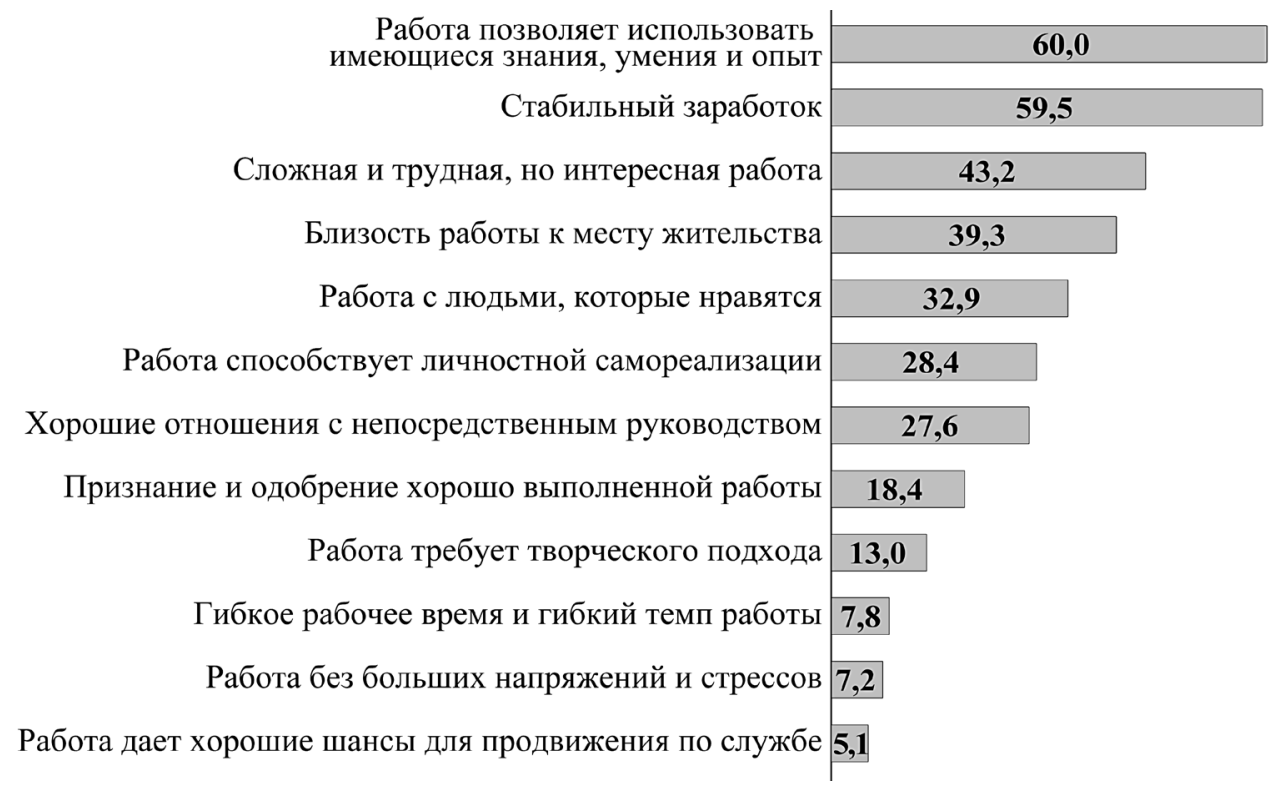

Рисунок 1. Иерархия факторов удовлетворенности работой медицинских работников, \% Примечание. Сумма процентов превышает 100, т. к. можно было выбрать до 6 вариантов ответа.

Работа требует большого напряжения, часто сопровождается стрессами

Высокая степень ответственности за результаты выполненной работы

На дорогу к работе приходится затрачивать много времени

Чтобы получить достойную зарплату, надо много и упорно трудиться

Однообразная работа

Жесткий график работы, нет возможности отвлечься на дела, напрямую не связанные с работой

Невнимательное отношение руководства к проблемам в труде и личной жизни Работа требует постоянного повышения квалификации Работа заставляет думать и действовать самостоятельно

Работа заставляет развивать свои способности, требует большого умственного напряжения

Коллеги думают только о себе, надеяться на их советы и помощь в работе не приходится

Для того, чтобы продвинуться по службе, надо много и долго работать
65,2

\section{6,2}

\section{3,9}

\section{2, 1}

\section{3,3}

12,9

11,0

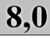

Рисунок 2. Иерархия факторов неудовлетворенности работой медицинских работников, \% Примечание. Сумма процентов превышает 100, т. к. можно было выбрать до 6 вариантов ответа. 
уступают ей на порядок. Второй по значимости фактор неудовлетворенности - «высокая степень ответственности за результаты выполненной работы», отнесенный нами к факторам-мотиваторам, - в равной мере присущ медикам, работающим во всех рассматриваемых типах медицинских учреждений, однако значимость этого фактора последовательно снижается по мере перехода от верхней к нижней ступени служебной лестницы (для главврачей $-33 \%$, а для ММП - 7\%).

Для более выверенного рассмотрения роли указанных факторов был проведен кластерный анализ. В результате иерархической кластеризации с использованием связывания посредством метода complete linkage или «самого дальнего соседа» как более осторожного были выявлены три кластера по каждому перечню факторов удовлетворенности и неудовлетворенности работой (таблица 7). Как и следовало ожидать, самые большие по размеру кластеры в обоих случаях оказались смешанHblмu, в них сочетаются факторы-мотиваторы и факторы гигиены (80\% по факторам удовлетворенности и $84 \%$ по факторам неудовлетворенности). Доля кластера «мотиваторов» составила 13\%, его образовали все $100 \%$ медицинских работников, которым нравится то, что работа требует творческого подхода, а также то, что она позволяет использовать имеющиеся знания, умения и опыт (75\%), является сложной, трудной, но интересной (66\%). Кластер, который был назван «гигиенисты» (7\%), образовали все $100 \%$ медицинских работников, указавших на положительное влияние гибкого рабочего времени и гибкого темпа работы, а также стабильного заработка (64\%).

Таблица 7. Представленность различных категорий медицинского персонала в кластерах по факторам удовлетворенности и неудовлетворенности работой, \%

\begin{tabular}{|l|c|c|c|c|c|c|}
\hline \multirow{2}{*}{ Категории } & \multicolumn{3}{|c|}{$\begin{array}{c}\text { Кластеры по факторам } \\
\text { удовлетворенности работой }\end{array}$} & \multicolumn{2}{c|}{$\begin{array}{c}\text { Кластеры по факторам } \\
\text { неудлетвонности работой }\end{array}$} \\
\cline { 2 - 7 } & $\begin{array}{c}\text { Мотива- } \\
\text { торы }\end{array}$ & $\begin{array}{c}\text { Смешан- } \\
\text { ный }\end{array}$ & Гигиенисты & $\begin{array}{c}\text { Мотива- } \\
\text { торы }\end{array}$ & $\begin{array}{c}\text { Смешан- } \\
\text { ный }\end{array}$ & Гигиенисты \\
\hline $\begin{array}{l}\text { Главврачи } \\
(3 \%)^{7}\end{array}$ & 10 & 2 & 0 & 3 & 3 & 4 \\
\hline Врачи (54\%) & 72 & 53 & 40 & 69 & 52 & 56 \\
\hline СМП (30\%) & 15 & 32 & 37 & 19 & 32 & 29 \\
\hline ММП (13\%) & 3 & 13 & 23 & 9 & 13 & 11 \\
\hline Всего & 100 & 100 & 100 & 100 & 100 & 100 \\
\hline $\begin{array}{l}\text { Численность } \\
\text { кластера, } \\
\text { чел. }\end{array}$ & $\mathbf{2 6 3}$ & $\mathbf{1 6 2 4}$ & $\mathbf{1 4 4}$ & $\mathbf{2 2 9}$ & $\mathbf{1 6 8 9}$ & $\mathbf{1 1 3}$ \\
\hline
\end{tabular}

7 В скобках указываются доли категорий в общей выборке. 
Аналогичным образом были образованы «зеркальные» по отношению к первому кластеры, вызывающие неудовлетворенность работой. Доля кластера «мотиваторов» составила 11\%. Образовавшая его компонента (100\%) указывает на неудовлетворенность жестким графиком работы и дополняется неудовлетворенностью напряженностью и стрессами на работе (72\%) при нулевом уровне неудовлетворенности тем, что работа заставляет развивать свои способности, требует большого умственного напряжения. Кластер «гигиенистов» образован на 100\%-м уровне неудовлетворенности тем, что работа заставляет развивать свои способности, требует большого умственного напряжения, а также ее напряженностью и стрессами $(69 \%)$.

Главврачи и врачи в существенно большей мере представлены в кластере «мотиваторов», а среди «гигиенистов» преобладают представители СМП и ММП. Кластеры, образованные на факторах удовлетворенности работой, оказались более информативными и были использованы в дальнейшем анализе. Удалось выявить особенности взаимосвязей кластеров «мотиваторов» и «гигиенистов» с результирующими показателями трудового поведения. К ним могут быть отнесены проявления зависимости размера оплаты труда от различных факторов. Выявлено, что «мотиваторы» в два раза чаще считают, что размер их заработной платы значительно зависит от личного трудового вклада по сравнению с кластером «гигиенистов» (41 и 21\% соответственно), от квалификации (33 и 15\% соответственно), от установленных эффективным контрактом целевых показателей (57 и 37\% соответственно). Вместе с тем, вопреки ожиданиям, не установлено влияние принадлежности к «мотиваторам» на готовность работать больше и лучше. Напротив, «мотиваторы» чаще по сравнению с «гигиенистами» утверждают, что работают в полную меру сил и способностей (67 и 53\% соответственно), и реже - что могут работать гораздо лучше, чем сейчас (10 и 13\% соответственно). Таким образом, кластер «мотиваторов» демонстрирует достигнутые результаты, но не готовность повышать свою трудовую отдачу в дальнейшем.

\section{Выводы}

Проведенный анализ позволяет утверждать, что ядро определяющих мотивов профессиональной деятельности медицинских работников (за исключением отдельных категорий, указанных выше) применительно к реальной ситуации работы образуют профессиональный интерес, сострадание и помощь больному, возможность заработать деньги. На периферии значимости оказались мотивы карьеры, расширения возможностей для общения и достижения уважения со стороны коллег ${ }^{8}$. Ядро ведущих стимулов к хорошей работе составляют справедливая оплата труда, наличие хорошего современного оборудования, создание возможностей для профессионального роста и повышения квалификации, тогда как на периферии значимости остались стимулы расширения самостоятельности в работе,

\footnotetext{
8 К ядру мотивации труда были отнесены три первых по рангу значимости мотива, стимулы, факторы удовлетворенности трудом, а к периферии - три последних из оцениваемых в 2014, 2016, 2018 гг. списков по трем основным вопросам о мотивации профессиональной деятельности медицинских работников.
} 
профессиональной переаттестации и легализации неформальных платежей. Обнаруженные позиции ядра и периферии стимулов имеют равное отношение ко всем выделяемым в исследовании категориям медицинских работников. Наконец, в ядро факторов, повышающих удовлетворенность работой, вошли возможность использовать имеющиеся знания, умения и опыт; стабильный заработок, наличие сложной, трудной, но интересной работы, а на периферийных местах - гибкость рабочего времени и темпов работы, отсутствие больших напряжений и стрессов в работе, наличие хороших шансов для продвижения по службе.

Выявленный в исследованиях состав ядра мотивов, стимулов и факторов удовлетворенности работой медицинских работников указывает на устойчивое воспроизводство в разных вариациях ведущей роли двух сторон труда - интересной по содержанию работы и ее достойной оплаты. Все, что касается роста потенциала мотивации достижения и самоутверждающего поведения (карьера, самостоятельность в работе, переаттестация, гибкость рабочего времени и темпов в работе), оказалось на периферии значимости мотивов, стимулов и факторов удовлетворенности.

Ожидаемая самодетерминация ведущих стимулов к хорошей работе и факторов удовлетворенности трудом не наблюдается. Вместо предполагаемых положительных связей ведущих стимулов и кластера «мотиваторов» медицинских работников с указаниями на больший уровень готовности работать гораздо лучше, чем сейчас, наблюдается их смещение к демонстрации, что они уже работают в полную меру сил и способностей, на высоком уровне качества и результативности.

В этой связи трудно надеяться на дальнейший рост трудовой отдачи медиков в условиях пандемии COVID-19 под влиянием денежных выплат; у абсолютного большинства из них ресурсы оказались исчерпанными в результате прошедших реформ. Предполагается, что относительные успехи в борьбе с пандемией российской медицины в сравнении с американской достигаются не за счет денежных доплат, а во многом благодаря инерции сохранившихся с советского времени традиций и практик мобилизационной медицины, наличия в ядре определяющих мотивов помимо денежного интереса, ценностей профессионализма и сострадания к больному.

В целом сложившуюся структуру мотивации профессиональной деятельности медицинских работников бюджетной сферы можно назвать консервативной, т. е. обладающей механизмами по сдерживанию радикальных шагов в сторону возможных изменений в процессе проводимых и будущих реформ. Вектор направленности такой структуры обращен не к изысканию внутренних резервов, а к государству, к возвращению с его стороны тех долгов перед медицинскими работниками (как материальных, так и моральных), которые накопились за десятилетия либеральных реформ.

Все более дефицитным становится важнейший для медицинских работников мотив сострадания и помощи больному. Несомненно, этот мотив имеет для всех терминальное и универсальное значение. В исследовании показана его относительно автономная роль как фактора выстраивания конструктивных практик в отношениях с пациентами. К сожалению, этот мотив пока чаще остается заметным в регионах с более низким уровнем экономического развития и зарплат медиков (Воронежская область) и реже в таких регионах, как Москва. 


\section{Литература}

Лопатина Н.Л. (2009) Культурологические аспекты в развитии сестринского дела. Кемерово: Аксиома.

Мансуров В.А., Юрченко О.В. (2005) Перспективы профессионализации российских врачей в реформирующемся обществе // Социологические исследования. № 1. С. 66-77.

Мансуров В.А., Юрченко О.В. (2010) Профессиональная идеология альтруизма российских врачей // Вестник Института социологии РАН. № 1. С. 397-410.

Маслоу А. (2016) Мотивация и личность. СПб.: Питер.

Николаев В.Г. (2015) Реформа российского здравоохранения и ценностные конфликты профессионализма // Журнал исследований социальной политики. Т. 13. № 4. С. 611-626.

Осин Е.Г., Иванова Т.Ю., Гордеева Т.О. (2013) Автономная и контролируемая профессиональная мотивация как предикторы субъективного благополучия у сотрудников российских организаций // Организационная психология. Т. 3. № 1. С. 8-29.

Поскотина М.И. (2009) Почему милосердие покинуло медицину // Сибирский педагогический журнал. № 12. С. 364-372.

Регионы России. Социально-экономические показатели (2019). Статистический сборник. М.: Росстат.

Семина Т.В. (2016) Социальный конфликт «врач-пациент» в современном российском обществе: объективные причины и субъективные факторы // Вестник Московского университета. Серия 18: Социология и политология. № 1. С. 84-106.

Стародубов В.И., Кадыров Ф.Н. (2013) Эффективный контракт в здравоохранении: возможности и риски // Менеджмент в здравоохранении. № 3. С. 6-15.

Темницкий А.Л. (2017) Феномен справедливости в оплате труда медицинских работников // Мир России. Т. 26. № 3. С. 64-89. DOI: 10.17323/1811-038X-2017-26-3-64-89

Темницкий А.Л. (2018) Изменения в мотивации труда врачей в условиях внедрения эффективного контракта // Социологические исследования. № 4. С. 90-102.

Темницкий А.Л. (2019) Социокультурный феномен самостоятельности в работе россиян в межстрановом сравнении // Социологические исследования. № 6. С. 37-49.

Херцберг Ф., Моснер Б., Блох Снидерман Б. (2007) Мотивация к работе. М., СПб.: Вершина.

Хуснутдинова Г.А., Хайруллина Ю.Р. (2020) Мобилизационная медицина: социальный портрет медицинского работника в современных условиях // Электронный экономический вестник. № 1. С. 71-78.

Чирикова А.Е. (1) (2019) О мотивации российских врачей: мифы и реалии // Интеракция. Интервью. Интерпретация. Т.11. № 20. С. 54-76.

Чирикова А.Е. (2) (2019) О полимотивации врачей: уроки реформ // Мир России. № 3. C. 6-26. DOI: 10.17323/1811-038X-2019-28-3-6-26

Шишкин С.В., Темницкий А.Л. (2020) Результативность введения эффективного контракта с медицинскими работниками // Экономическая политика. Т. 15. № 3. С. 176-203.

Шишкин С.В., Темницкий А.Л. Чирикова А.Е. (2013) Стратегия перехода к эффективному контракту и особенности трудовой мотивации медицинских работников // Экономическая политика. № 4. С. 27-53.

Deci E., Ryan R.M. (1985) Intrinsic Motivation and Self-Determination in Human Behavior, New York, NY: Plenum.

Dolea C., Adams O. (2005) Motivation of Health Care Workers - Review of Theories and Empirical Evidence // Cahiers de Sociologie et Demographie Medicale, no 45, pp. 135-161.

Franco L.M., Bennett S., Kanfer R. (2002) Health Sector Reform and Public Sector Health Worker Motivation: A Conceptual Framework // Social Science \& Medicine, vol. 54, no 8, pp. $1255-1266$.

Ryan R.M., Deci E.L (2000) Self-Determination Theory and the Facilitation of Intrinsic Motivation, Social Development and Well-Being // American Psychologist, vol. 55, no 1, pp. 68-78.

Ryan R.M., Deci E.L. (2017) Self-determination Theory: Basic Psychological Needs in Motivation, Development, and Wellness, New York. 


\title{
The Motivational Structure of Healthcare Professionals in Russia
}

\author{
A. TEMNITSKIY*
}

\begin{abstract}
*Alexander Temnitskiy - PhD in Sociology, Associate Professor, Sociological Department, Moscow State Institute of International Relations (MGIMO); Senior Researcher, Institute of Sociology of the FCTAS RAS. Address: 76 Vernadskogo Ave., Moscow, 119454, Russian Federation. E-mail: taleksandr@list.ru
\end{abstract}

Citation: Temnitskiy A. (2021) The Motivational Structure of Healthcare Professionals in Russia. Mir Rossii, vol. 30, no 4, pp. 30-52 (in Russian). DOI: $10.17323 / 1811-038 X-2021-30-4-30-52$

\begin{abstract}
This study focuses on the motivational structure of healthcare professionals, the role of their motives, intentions, incentives and satisfaction with various aspects of their work, and their connection with the motive of compassion. Special attention is paid to identifying the stability of the motivational structure over time and in relation to control factors such as status, regional, organizational and qualification affiliation, as well as the gender and age of healthcare professionals. For each component of the motivational structure, a set of its measurement indicators is proposed. Maslow's hierarchy forms the basis for identifying work motives-incentives. Two groups of external motivating factors are identified: (1) equal conditions for improving professional activity and (2) the means for activating internal resources. The factors of work satisfaction and dissatisfaction are identified using Herzberg's theory. To test the hypotheses regarding the internalization of norms set by incentives and the factors of work satisfaction, provisions from self-determination theory were applied.

Empirically we draw on data from three repeated sociological studies conducted in the same three regions of Russia in 2014-2018 funded through the program for fundamental research at HSE University.

The findings reveal the sustainable reproduction of each of the components of the motivational structure: an interesting job in terms of the content and a fair wage. The manifestations of achievement motivation are only marginally significant, as is the expected self-determination of leading incentives for good work and the factors of work satisfaction. The motivational structure of public healthcare professionals was thus characterized as conservative. The motive of compassion is becoming more and more scarce, but as the analysis shows, it is a reliable factor in arranging constructive practices in relations with patients.
\end{abstract}

Keywords: motivation structure, determining motives, work incentives, work satisfaction, factors-motivators, hygiene factors, motive of mercy, self-determination theory, healthcare professionals 


\section{References}

Chirikova A.E. (1) (2019) O motivacii rossijskih vrachej: mify i realii [On the motivation of Russian Doctors: Myths and Realities]. Interakciya. Interv'yu. Interpretaciya, vol. 11, no 20 , pp. 54-76.

Chirikova A.E. (2) (2019) O polimotivacii vrachej: uroki reform [On Polymotivating Doctors: Lessons from Reform]. Mir Rossii, no3,pp.6-26.DOI: 10.17323/1811-038X-2019-28-3-6-26

Deci E., Ryan R.M. (1985) Intrinsic Motivation and Self-Determination in Human Behavior, New York, NY: Plenum.

Dolea C., Adams O. (2005) Motivation of Health Care Workers - Review of Theories and Empirical Evidence. Cahiers de Sociologie et Demographie Medicale, no 45, pp. 135-161.

Franco L.M., Bennett S., Kanfer R. (2002) Health Sector Reform and Public Sector Health Worker Motivation: A Conceptual Framework. Social Science \& Medicine, vol. 54, no 8, pp. $1255-1266$.

Hercberg F., Mosner B., Bloh Sniderman B. (2007) Motivaciya k rabote [Motivation to Work], Moscow, Saint Petersburg: Vershina.

Khusnutdinova G.A., Khajrullina Yu.R. (2020) Mobilizacionnaya medicina: social'nyj portret medicinskogo rabotnika $\mathrm{v}$ sovremennyh usloviyah [Mobilization Medicine: A Social Portrait of a Medical Worker in Modern Conditions]. Elektronnyj ekonomicheskij vestnik, no 1 , pp. 71-78.

Lopatina N.L. (2009) Kul'turologicheskie aspekty v razvitii sestrinskogo dela [Cultural Aspects in the Development of Nursing], Kemerovo: Aksioma.

Mansurov V.A., Yurchenko O.V. (2005) Perspektivy professionalizacii rossijskih vrachej $\mathrm{v}$ reformiruyushchemsya obshchestve [Prospects for the Professionalization of Russian Doctors in a Reforming Society]. Sociologicheskie issledovaniya, no 1, pp. 66-77.

Mansurov V.A., Yurchenko O.V. (2010) Professional'naya ideologiya al'truizma rossijskih vrachej [Professional Ideology of Altruism of Russian Doctors]. Vestnik Instituta sociologii $R A N$, no 1 , pp. 397-410.

Maslow A. (2016) Motivaciya i lichnost' [Motivation and Personality], Saint Petersburg: Piter.

Nikolaev V.G. (2015) Reforma rossijskogo zdravoohraneniya i cennostnye konflikty professionalizma [Reform of Russian Healthcare and Value Conflicts of Professionalism]. Zhurnal issledovanij social'noj politiki, vol. 13, no 4. pp. 611-626.

Osin E.G., Ivanova T.Yu., Gordeeva T.O. (2013) Avtonomnaya i kontroliruemaya professional'naya motivaciya kak prediktory sub"ektivnogo blagopoluchiya u sotrudnikov rossijskih organizacij [Autonomous and Controlled Professional Motivation as Predictors of Subjective Well-Being in Employees of Russian Organizations]. Organizacionnaya psikhologiya, vol. 3, no 1, pp. 8-29.

Poskotina M.I. (2009) Pochemu miloserdie pokinulo medicinu [Why Mercy Left Medicine]. Sibirskij pedagogicheskij zhurnal, no 12, pp. 364-372.

Regiony Rossii. Social'no-ekonomicheskie pokazateli. Statisticheskij sbornik [Regions of Russia. Socio-economic Indicators. Statistical Collection] (2019), Moscow: Rosstat.

Ryan R.M., Deci E.L (2000) Self-Determination Theory and the Facilitation of Intrinsic Motivation, Social Development and Well-Being. American Psychologist, vol. 55, no 1, pp. 68-78.

Ryan R.M., Deci E.L. (2017) Self-determination Theory: Basic Psychological Needs in Motivation, Development, and Wellness, New York.

Semina T.V. (2016) Social'nyj konflikt «vrach-pacient» v sovremennom rossijskom obshchestve: ob"ektivnye prichiny i sub"ektivnye faktory [Social Conflict "Doctor-Patient" in Modern Russian Society: Objective Reasons and Subjective Factors]. Vestnik Moskovskogo universiteta. Seriya 18: Sociologiya i politologiya, no 1, pp. 84-106.

Shishkin S.V., Temnitskiy A.L. (2020) Rezul'tativnost' vvedeniya effektivnogo kontrakta $\mathrm{s}$ medicinskimi rabotnikami [The Effectiveness of Performance-Based Employment Contracts with Medical Professionals]. Ekonomicheskaya politika, vol. 15, no 3, pp. 176-203.

Shishkin S.V., Temnitskiy A.L., Chirikova A.E. (2013) Strategiya perekhoda k effektivnomu kontraktu i osobennosti trudovoj motivacii medicinskih rabotnikov [The Strategy 
of Transition to Performance-Based Employment Contracts and the Features of Labor Motivation of Medical Workers]. Ekonomicheskaya politika, no 4, pp. 27-53.

Starodubov V., Kadirov F. (2013) Effektivnyj kontrakt v zdravoohranenii: vozmozhnosti i riski [Performance-Based Employment Contract in Health Care: Opportunities and Risks]. Menedzhment $v$ zdravoohranenii, no 3, pp. 6-15.

Temnitskiy A.L. (2017) Fenomen spravedlivosti v oplate truda medicinskih rabotnikov [The Phenomenon of Justice in the Wages of Medical Workers]. Mir Rossii, vol. 26, no 3, pp. 64-89. DOI: 10.17323/1811-038X-2017-26-3-64-89

Temnitskiy A.L. (2019) Sociokul'turnyj fenomen samostoyatel'nosti v rabote rossiyan v mezhstranovom sravnenii [The Sociocultural Phenomenon of Self-Dependence in Work among Russians in the International Comparison]. Sociologicheskie issledovaniya, no 6, pp. $37-49$.

Temnitskiy A.L. (2018) Izmeneniya v motivacii truda vrachej v usloviyah vnedreniya effektivnogo kontrakta [Changes in Doctors' Motivation in the Context of Transition Towards Performance-Based Employment Contracts]. Sociologicheskie issledovaniya, no 4, pp. $90-102$. 